\title{
EDUKASI ETIKA BERKOMUNIKASI \\ PADA ANAK USIA 10-14 TAHUN DI YAYASAN DESA HIJAU
}

\author{
${ }^{1)}$ Gina Siti Kamilah, ${ }^{2)}$ Euis Mediawati, ${ }^{3)}$ Herti Kristiani Zalukhu, ${ }^{4)}$ Siti Qowiatun, \\ ${ }^{5)}$ Windy Nur Antika dan ${ }^{6)}$ Yenni Siregar \\ Mahasiswa Prodi Sekretari D-III Universitas Pamulang \\ ginaskamilah12@gmail.com
}

\begin{abstract}
ABSTRAK
Edukasi Etika Berkomunikasi merupakan suatu aktivitas yang sangat sering dilakukan oleh setiap orang dalam lingkungan apa pun,di mana pun dan kapan pun, karena komunikasi sangat penting bagi kehidupan kita. Dengan mengedukasikan etika berkomunikasi pada anak di era globalisasi ini telah menyimpang dari ajaran tentang tingkah laku hidup atau ajaran agama tertentu yang berlaku di dalam lingkungan masyarakat, maka dengan mudah berkomunikasi dengan baik dilingkungan masyarakat. Tujuan Etika Berkomunikasi adalah untuk menciptakan etika atau kesopanan dalam berkomunikasi dan menciptakan kesan yang baik atau sesuai dengan apa yang diharapkan dari pihak-pihak yang berkomunikasi. Upaya yang dilakukan untuk menanamkan pemahaman etika yang baik dengan cara menasihati dan mengedukasikan cara berkomunikasi yang baik. Tujuan dari kami adalah untuk menjadikan mereka generasi yang mempunyai nilai kesopanan yang tinggi dan bermartabat kelak. Pelaksanaan PKM dilakukan hari sabtu tanggal 28 Agustus 2021 dari jam 10.00 hingga pukul 11.43. Setelah diberikan materi pada siswa Yayasan Desa Hijau para siswa diberikan pertanyaan supaya para siswa lebih memahami tentang Etika Berkomunikasi yang baik dan benar. Kesimpulan dari kegiatan pengabdian kepada masyarakat ini mengimplementasikan etika berkomunikasi kepada siswa Yayasan Desa Hijau supaya mereka dapat berkomunikasi dengan baik kepada guru,orang tua dan teman.
\end{abstract}

\section{Kata Kunci: Edukasi, Etika, Berkomunikasi, dan Siswa}

\section{ABSTRACT}

Ethical Education Communication is an activity that is very often carried out by everyone in any environment, anywhere and anytime, because communication is very important for our lives. By educating children about communication ethics in this era of globalization, they have deviated from teachings about life behavior or certain religious teachings that apply in society, making it easy to communicate well in society. The purpose of Communicating Ethics is to create ethics or politeness in communicating and create a good impression or in accordance with what is expected of the communicating party. Efforts are being made to instill a good ethical understanding by advising and educating on good communication methods. Our goal is to make them a generation that has high moral values and dignity in the future. The implementation is carried out on Saturday, August 28, 2021, from 10.00 to 11.43. after being given material to the students of the Green Village Foundation, students were given questions so that students better understand good and correct Communication Ethics. The conclusion of this community service activity is to apply communication ethics to Green Village Foundation students so that they can communicate well with teachers, parents and friends.

Keywords: Education, Ethics, Communication, and Students 


\section{PENDAHULUAN}

Pengabdian Kepada Masyarakat (PKM) adalah suatu kegiatan yang bertujuan membantu masyarakat tertentu dalam beberapa aktivitas tanpa mengharapkan imbalan dalam bentuk apapun. Secara umum program ini dirancang oleh berbagai universitas yang ada di Indonesia untuk memberikan kontribusi nyata bagi bangsa Indonesia. Program Kreativitas Mahasiswa merupakan salah satu bagian dari Universitas Pamulang.

Tujuan yang ingin dicapai dari Pengabdian Kepada Masyarakat ini secara umum adalah meningkatkan kesadaran etika berkomunikasi yang baik, setiap kegiatan yang dilakukan diharapkan akan memberikan manfaat, demikian halnya kegiatan Pengabdian Kepada Masyarakat yang diselenggarakan oleh Universitas Pamulang Kepada Anak-anak Yayasan Desa Hijau.

Pengabdian Kepada Masyarakat adalah suatu kegiatan akademik yang dilaksanakan oleh Mahasiswa Universitas Pengabdian Kepada Masyarakat tercantum dalam pasal 20 Undang-undang No.20 Tahun 2003 tentang sistem Pendidikan Nasional (UU Diknas) dan berdasarkan pasal 24 Undang-Undang Diknas. Dengan adanya Pengabdian Kepada Masyarakat diharapkan mampu berinteraksi serta dapat memberikan kontribusi positif kepada masyarakat. Harapan tersebut merupakan tujuan utama dari Pengabdian Kepada Masyarakat ini.

Dalam upaya meningkatkan dan menumbuhkan Kreativitas Mahasiswa serta keikutsertaan maka kami mengadakan kegiatan PKM ini di Yayasan Desa Hijau, Tangerang Selatan. Kegiatan berlangsung 1 hari pada tanggal 28 Agustus 2021 dengan judul "Edukasi Etika Berkomunikasi Pada Anak Usia 10-14 Tahun Di Yayasan Desa hijau" untuk menciptakan pelayanan prima, seluruh Mahasiswa PKM Akademik D-III sekretari/Ekonomi yang berhubungan langsung dengan Siswa/I Yayasan Desa Hijau harus mempunyai ide-ide yang baik, sehingga dalam berinteraksi dengan Siswa/I dapat memberikan layanan prima, dan hal ini dapat membangun kepuasan pada setiap Siswa/i.

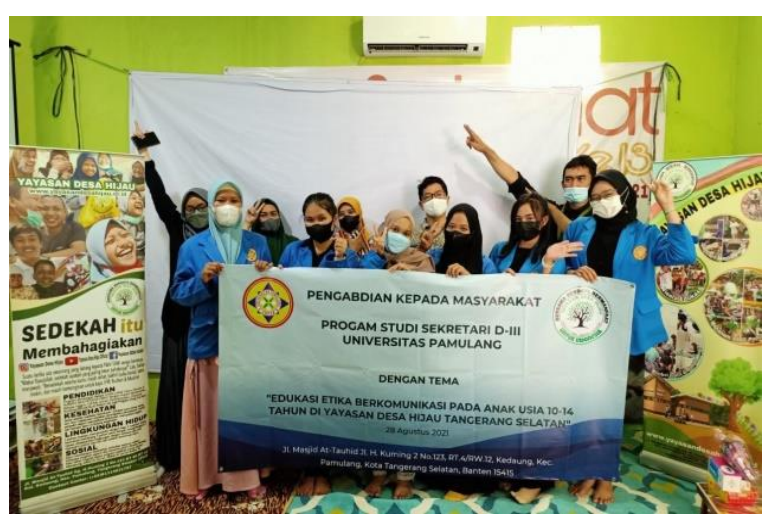

Gambar 1. Panitia PKM Prodi Sekretari D-III 


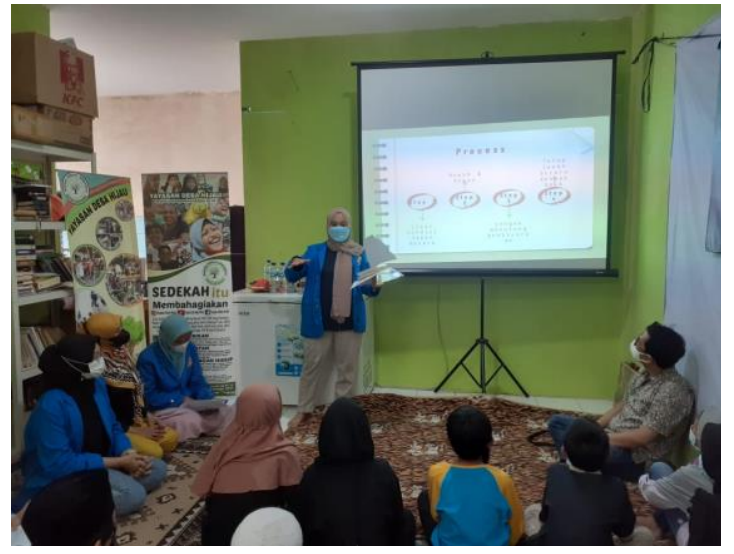

Gambar 2. Pemaparan Materi Edukasi Etika Berkomunikasi

Dalam rangka melaksanakan Pengabdian Kepada Masyarakat, maka kami Mahasiswa Prodi Sekretari Fakultas Ekonomi Universitas Pamulang melaksanakan Pengabdian Kepada Masyarakat mengenai etika berkomunikasi Pada Anak Usia 10-14 Tahun Di Yayasan Desa Hijau, kami sebagai Mahasiswa memberikan ilmu pengetahuan secara akademik dalam memahami Perilaku yang baik serta adanya kemajuan pola pikir untuk masa depan.

\section{METODE PELAKSANAAN}

Sebelum PKM dilaksanakan kami melakukan survey ke Yayasan Desa Hijau dan mengamati apa saja permasalahan yang ada, maka kami sepakat untuk mengambil judul Pengabdian Kepada Masyarakat sebagai berikut: "Edukasi Etika
Berkomunikasi Pada Anak Usia 10-14 Tahun". Langkah berikut yang kami lakukan adalah dengan membuat proposal PKM yang kami ajukan kepada Dosen Pembimbing Akademik (PA). Proposal PKM yang diajukan kemudian akan di review oleh reviewer untuk kemudian disetujui oleh Ketua Program Studi Sekretari D-III Universitas Pamulang.

Setelah proposal PKM disetujui oleh Ketua Program Studi Sekretari D-III Universitas Pamulang, maka kami melakukan berbagai persiapan terutama menyiapkan materi yang akan kami sampaikan pada Pengabdian Kepada Masyarakat untuk mengedukasikan etika berkomunikasi pada siswa.Kegiatan Pengabdian Kepada Masyarakat (PKM) yang dilaksanakan pada tanggal 28 Agustus 2021 telah berjalan dengan baik dan lancar. Sebelum tanggal tersebut juga dilakukan komunikasi secara intens sebagai analisis awal. Kegiatan ini diikuti Ketua Yayasan Desa Hijau, Pengurus Yayasan ,Guru dan Anakanak Yayasan Desa Hijau,

Berikut tahapan kegiatan Pengabdian Kepada Masyarakat (PKM) yang dilakukan sebagai berikut:

\section{Tahap Persiapan}



a. Survei lokasi
b. Pemantapan penentuan lokasi
c. Menyerahkan proposal kepada pihak Yayasan
d. Mempersiapkan materi

\section{HASIL DAN PEMBAHASAN}

Hasil pembahasan dalam usaha untuk mendapatkan data terkait dengan Strategi dan Tantangan edukasi etika berkomunikasi pada anak di Yayasan desa hijau, FaktorFaktor Internal yang Mempengaruhi etika berkomunikasi anak diantaranya ialah :

1. Minimnya peran orang tua dalam mengarahkan etika lewat mengajarkan dan mencontohkan kepada anak.

Orangtua memegang peranan penting untuk mengembangkan potensi anaknya. Orangtua merupakan pendidik pertama dan utama dalam lingkungan keluarga, orang tua perlu sadar bahwa anak memiliki potensi besar saat dilahirkan. Pentingnya pendidikan anak usia remaja karena pada periode tersebut perkembangan anak berjalan semakin pesat. Agar edukasi etika berkomunikasi dapat berjalan secara komprehensif pada anak, diperlukan kerja sama, kesadaran serta pembinaan kepada para orang tua agar timbul kesadaran bersama akan pentingnya edukasi berkomunikasi pada anak-anak mereka di usia 1014 tahun. Berdasarkan wawancara langsung dengan pengurus yayasan desa hijau etika berkomunikasi yang ada pada pada anak binaan masih belum baik hal ini terlihat dari bagaimana ketika praktek langsung terlihat masih ada yang belum mengetahui. Berangkat dari hal tersebutlah kiranya perlu juga di lakukan arahan kepada orang tua akan edukasi etika berkomunikasi yang baik pada anak-anak mereka.

2. Pengaruh lingkungan pertemanan yang kurang baik

Dalam perkembangan sosial pada anak, teman sebaya sangatlah berperan penting. Peranan teman sebaya terhadap anak terutama berkaitan dengan sikap, pembicaraan, minat, penampilan, dan perilaku. Seorang anak sering kali menilai bahwa bila dirinya memakai model pakaian yang sama dengan anggota kelompok yang populer, maka kesempatan baginya untuk diterima oleh teman-teman sebayanya menjadi besar. Sama halnya dengan komunikasi pada anak, lingkungan menjadi faktor 
yang besar dalam mempengaruhi

etika komunikasi baik kepada

teman terlebih kepada orang yang

lebih tua. Berdasarkan hasil

wawancara dengan pengurus

yayasan desa hijau, masih terdapat

anak yang masih berbicara dengan

nada tinggi dan kasar kepada teman

bahkan orang yang lebih tua, hal ini

perlu di lakukan pembinaan serta

pelatihan yang berkesinambungan

guna mengurangi pengaruh

lingkungan yang tidak baik.

3. Kemajuan teknologi informasi

Hampir segala hal yang ada di dunia ini menjadi mungkin dan mudah dengan adanya teknologi. Teknologi dengan segala keanggunan dan kecanggihannya berhasil memikat berbagai kalangan usia mulai usia manula, dewasa, remaja, bahkan anak-anak. Orangtua kerap memfasilitasi putra-putri mereka yang masih belia dengan gadget atau barangbarang berbau teknologi lainnya untuk memanjakan putra-putri mereka seperti komputer dan handphone. Namun orangtua patut waspada terhadap fasilitas teknologi canggih yang mereka berikan kepada putra-putri mereka karena ternyata teknologi mampu membawa dampak negatif pada anak. Menurut hasil wawancara dengan pengurus yayasan desa hijau hampir 100\% anak-anak 1014 tahun telah mampu mengoprasikan gadget, mulai dari game, youtube bahkan social media. Penggunaan teknologi seperti gadget menjadikan etika komunikasi pada anak menjadi kurang. Hal ini terlihat dari sikap anak yang telihat lebih acuh dan tidak menatap mata lawan bicara saat berkomunikasi. Untuk mengatasi hal tersebut diperlukan sebuah pembinaan akan penggunaan teknologi serta lebih menggalakkan manfaat positif yang didapatkan dari teknologi informasi, seperti pembelajaran online \& sebagai jendela informasi pengetahuan.

4. Perlunya penambahan pemberian kajian keagamaan terkait ahklak dan etika.

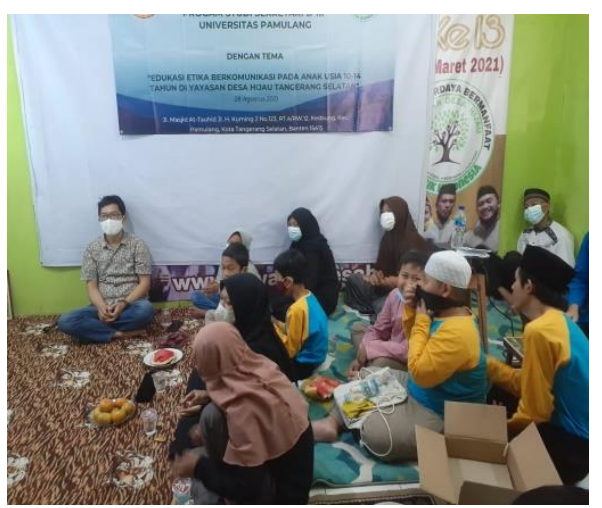


Gambar 3. Foto Anak Yayasan

Mendengarkan Pemaparan Materi

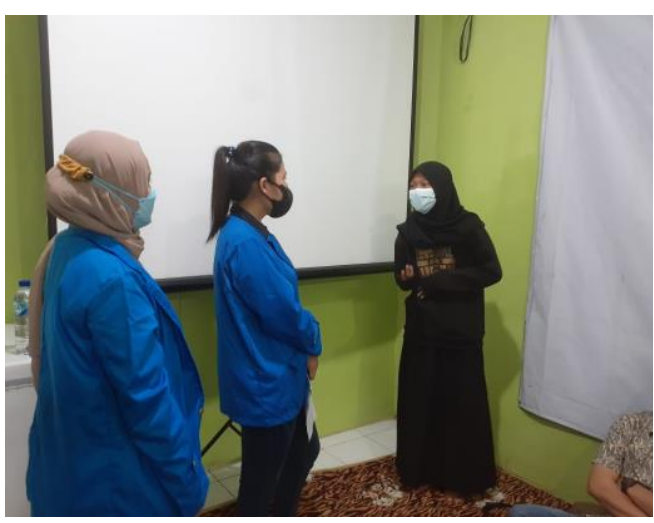

Gambar 4. Anak Yayasan Di Beri

Contoh Berkomunikasi Yang Baik

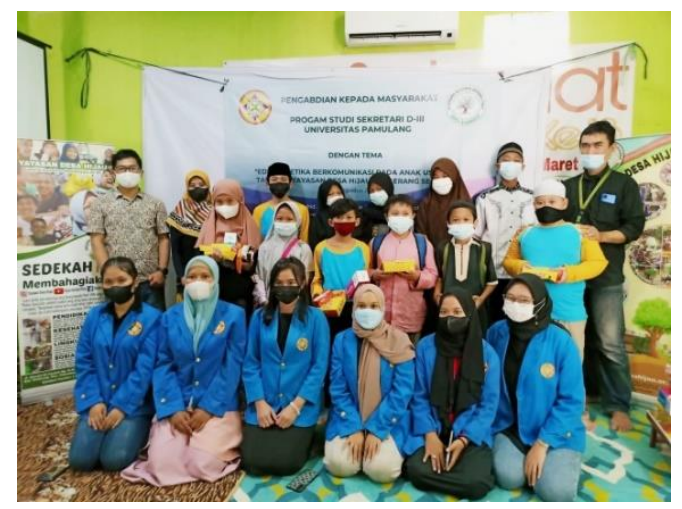

Gambar 5. Foto Bersama Pengurus Yayasan dan Anak-anak Yayasan Desa Hijau

\section{Visi Yayasan Desa Hijau}

Terwujudnya masyarakat yang peduli terhadap kelestarian lingkungan dan peduli terhadap sesama umat manusia.

\section{Misi Yayasan Desa Hijau}

a. Membangun kepedulian

Edukasi dan promosi kepada masyarakat. b. Kerjasama dan Kolaborasi. Keterbukaan dan ber-Bhineka Tunggal Ika.

c. Profesional dan Berdedikasi Pengabdian kepada masyarakat.

\section{KESIMPULAN DAN SARAN}

Berdasarkan hasil pelaporan dan pembahasan yang telah diuraikan oleh penulis, maka dapat diambil kesimpulan yaitu :

1. Etika berkomunikasi sangat penting bagi manusia karena dengan memahami etika berkomunikasi seseorang akan memiliki attitude yang baik dalam berbicara dengan lawan bicaranya serta memahami cara berbicara yang baik dan sopan.

Materi yang kami berikan tentang edukasi etika berkomunikasi diharapkan mampu menambah pengetahuan dan berguna bagi para siswi baik untuk sekarang maupun masa yang akan datang.

Selama pemberian materi dikelas Siswa/I sangat antusias, terutama dalam sesi tanya-jawab karena hal tersebut mereka dapat menggali informasi dan pengetahuan lebih banyak lagi.

Setelah melaksanakan

Pengabdian Kepada Masyarakat 
(PKM) dengan tema Edukasi Etika Berkomunikasi penulismemberikan saran:

1. Agar siswi lebih giat dalam belajar dan memahami apa yang telah diajarkan selama PKM maupun selama mereka belajar di sekolah.

2. Lebih mengembangkan potensi yang mereka miliki agar nantinya dapat berguna dalam dunia kerja khusunya di era modern ini.

\section{DAFTAR PUSTAKA}

Ngalimun. 2017. Ilmu Komunikasi : Sebuah Pengantar Praktis. Yogyakarta: Pustaka Ilmu.

Rohim, Syaiful. 2016. Teori Komunikasi : Perspektif, Ragam, dan Aplikasi. Edisi Revisi. Jakarta: Rineka Cipta.

Roudhonah. 2007. Ilmu Komunikasi. Jakarta: UIN Press.

Suranto, A.W. 2010. Komunikasi Sosial Budaya. Yogyakarta: Graha Ilmu.

West Richard, Tuner Lynn H. 2012. Pengantar Teori Komunikasi Analisis Dan Aplikasi. Jakarta : Salemba Humanika.

https://www.yayasandesahijau.or.id/te ntang-ydh.html. Diakses tanggal 5 September 2021.

https://phylo2.blogspot.com/2018/05/ 50-pengertian-pendidikanmenurut-para-ahli-danreferensinya.html. Diakses tanggal 5 September 2021. 